\title{
GSK-Binding Domain
}

National Cancer Institute

\section{Source}

National Cancer Institute. GSK-Binding Domain. NCI Thesaurus. Code C14104.

The GSK-Binding Domain of AXIN2 mediates interaction with GSK3-Beta. Involved in regulation of the WNT signaling pathway, AXIN2 organizes an APC/Beta-Catenin/GSK3Beta/ AXIN2 complex that leads to Beta-Catenin degradation. (NCI) 